\title{
Magnetic Properties of Biocompatible Magnetic Fluid after Electron Irradiation
}

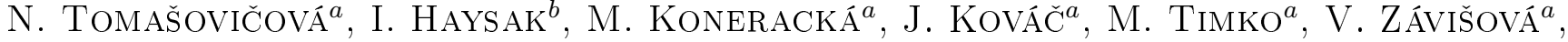

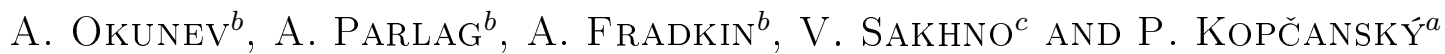 \\ ${ }^{a}$ Institute of Experimental Physics, Slovak Academy of Sciences, Watsonová 47, 04001 Košice, Slovakia \\ ${ }^{b}$ Uzhgorod National University, Kapitulna 9A, 88000 Uzhgorod, Ukraine \\ ${ }^{c}$ Institute for Nuclear Research, Ukrainian National Academy of Science, Prospekt Nauky 47, 03680 Kiev, Ukraine
}

\begin{abstract}
The magnetic particles in the water-based magnetic fluids were sterically stabilized by natrium oleate to prevent their agglomeration and consequently the adsorption of poly-ethylene-glycol (PEG) was carried out to improve the biocompatibility of the magnetic particles. Two sets of samples were prepared. The first set of the samples was with different molar weight of PEG ( $\mathrm{Mw}=400,1000,10000$ and 20000$)$ at the constant weight ratio of $\mathrm{PEG} / \mathrm{Fe}_{3} \mathrm{O}_{4}=0.25$ and the second one was with different weight ratio of $\mathrm{PEG} / \mathrm{Fe}_{3} \mathrm{O}_{4}$ and constant molar weight of PEG $(\mathrm{Mw}=1000)$. The samples were irradiated with $20 \mathrm{~Gy}$. The same reduction of saturated magnetization (about 10\%) after electron irradiation with 20 Gy was observed for all prepared samples.
\end{abstract}

PACS: 75.50.Mm, 61.80.Fe, 61.82.Rx

\section{Introduction}

Magnetic fluids, or ferrofluids as they are often called, mainly consist of nanosized iron oxide particles $\mathrm{Fe}_{3} \mathrm{O}_{4}$ or $\gamma-\mathrm{Fe}_{2} \mathrm{O}_{3}$ that are suspended in carrier liquid such as water, mineral oil, damping oil, paraffin, kerosene and so on. Because the size of the particles is in the colloidal range, i.e. between about 10 and $1000 \mathrm{~nm}$, these particles are often referred to as magnetic colloids. The modern era of ferrofluids manufacture begins when ferrofluids were made using colloidal stable particles using the co-precipitation technique $[1,2]$. This technique is still used today as a basis for producing high quality colloid suspensions of magnetic particles in a variety of liquid carrier fluids. Magnetic fluids offer some attractive possibilities in biomedicine as they have controllable size ranging from a few nanometers up to tens of nanometers. Indeed, they can be coated with biological molecules to make them interact with or bind to a biological entity. These properties make them very attractive for applications in biomedicine for example in drug targeting delivery, magnetic hyperthermia, arrangement of biological assemblies, repair of damaged retinas, contrast agents in magnetic resonance imaging (MRI), magnetic sealing of aneurysms, biomagnetic separation.

Biomedical applications require the magnetic particles to be stable in water at neutral $\mathrm{pH}$ and physiological salinity. Moreover, for in vivo applications the magnetic particles must be coated with biocompatible polymer $[3,4]$. From the point of basic and applied research it will be very interesting to study physical properties of magnetic fluids after electron radiation. Up to now there is very poor information about influence of radiation on the physical properties of magnetic fluids [5]. Magnetic hyperthermia is one of the widely studied application of magnetic fluids in medicine [6-9]. However, the combined hyperthermia and radiation up to 20 Gy was shown to be significantly more effective than with radiation alone [9].

In our previous work [10] we have studied the stability of magnetic properties of biocompatible water-based magnetic fluids with the magnetic particles stabilized by one surfactant - natrium oleate and by two surfactants - natrium oleate and PEG after irradiation up to 1000 Gy.

The aim of this paper was to study stability of magnetic properties of biocompatible water-based magnetic fluids suitable for bioaplications with the magnetic particles stabilized by two surfactants, natrium oleate and with PEG of different molar weight, as well as for different ratio of $\mathrm{PEG}$ and the magnetite after irradiation $20 \mathrm{~Gy}$.

\section{Experimental methods}

The magnetic $\mathrm{Fe}_{3} \mathrm{O}_{4}$ particles were synthesized by a chemical co-precipitation procedure [10]. The first set of the samples was prepared with different molar weight $\mathrm{Mw}$ of PEG $=400,1000,10000$ and 20000 at the weight ratio $(\mathrm{Wr})$ of $\mathrm{PEG} / \mathrm{Fe}_{3} \mathrm{O}_{4}=0.25$. The second set of the samples was prepared with molar weight of PEG $\mathrm{Mw}=1000$ and the $\mathrm{Wr}$ of $\mathrm{PEG} / \mathrm{Fe}_{3} \mathrm{O}_{4}$ was $0.25,0.5$, $0.75,1.0,1.2,1.5,2.0$, and 2.5 , respectively. These samples were 3 times diluted compared with previous set. The irradiation of samples was conducted by electrons on an accelerator "Microtron M-10" of Uzhgorod National University [10]. The magnetization curves of the samples before irradiation and after irradiation with different 
doses were measured by SQUID magnetometer (Quantum Design MPMS 5XL) twice. The second measurement was done one month after first measurement. The upper part of the samples, kept in screw capped vials, was withdrawn for measurements. The weight of measured samples varied from the interval $20-30 \mathrm{mg}$. The error of weight was $\pm 4 \%$ that influences values of magnetization measurements. The Fourier transform infrared (FTIR) spectra of the samples after irradiation were measured by FTIR spectrometer FTLA2000 instrument (ABB, resolution $4 \mathrm{~cm}^{-1}$ ) by Attenuated Total Reflectance measurements with diamond window. For infrared measurements the samples were first mixed and then dried.

\section{Results and discussion}

The prepared samples were irradiated with fluence $6.6 \times 10^{10}$ electrons $/ \mathrm{cm}^{2}$ that corresponds to dose $20 \mathrm{~Gy}$. After irradiation the samples were placed in the screw capped vials. One week after irradiation the upper part of the samples was withdrawn for the magnetization measurements. This procedure was repeated one month later. The saturating magnetization of the set of samples with different molar weight (400, 1000, 10000 and 20000) before irradiation had the same value.

Figure 1 shows the magnetization curves of the sample with molar weight 400 before irradiation and samples with the different molar weight of PEG after irradiation with 20 Gy measured one week after irradiation. The obtained results showed about $10 \%$ reduction of the saturated magnetization after irradiation, but this reduction is the same for all prepared samples. These results suggest that there is no influence of the molar weight of PEG on the magnetic properties of the magnetic fluids. The same results were obtained also from the measurements done one month after the first measurement. The obtained results showed that after first sedimentation caused by irradiation, the all samples are time stable.

The next set of samples with different Wr of PEG/ $\mathrm{Fe}_{3} \mathrm{O}_{4}$ were irradiated with the same dose, i.e. 20 Gy. The obtained values of the saturated magnetization before and after irradiation are summarized in Fig. 2. The obtained results show about $10 \%$ reduction in the saturated magnetization off all samples and no change between 1st and 2nd measurement.

We suppose that process at the used electron energy is ionization [10] that could lead to the aggregation of the particles. After first sedimentation that occurs after irradiation there is no additional sedimentation and samples are time stable. Figure 3 shows the infrared spectra of magnetic particles coated with natrium oleate and PEG (molar weight 1000 and $0.25 \mathrm{~g}$ PEG per $1 \mathrm{~g}$ of $\mathrm{Fe}_{3} \mathrm{O}_{4}$ ) before irradiation and after irradiation. The all absorption bands corresponding to the natrium oleate or PEG as well as the band observed at $584 \mathrm{~cm}^{-1}$, which corresponds to the magnetite, before irradiation and after irradiation are identical. The same results were obtained for all samples. These results confirmed that the molecules

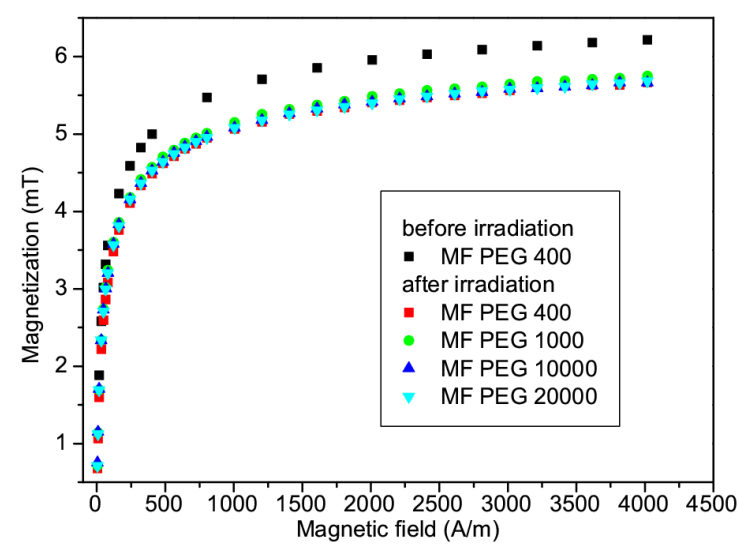

Fig. 1. Magnetization curves of the water-based magnetic fluid containing the magnetic particles coated with natrium oleate and PEG with molar weight 400 before irradiation and PEG with different molar weight after irradiation with 20 Gy measured one week after irradiation and one month after first measurement.

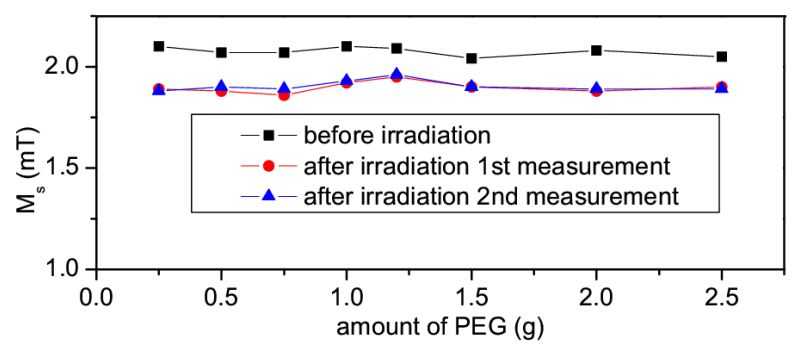

Fig. 2. The saturated magnetization of the samples with different amount of PEG surfactant before and after irradiation from the first measurements and from the measurements one month later.

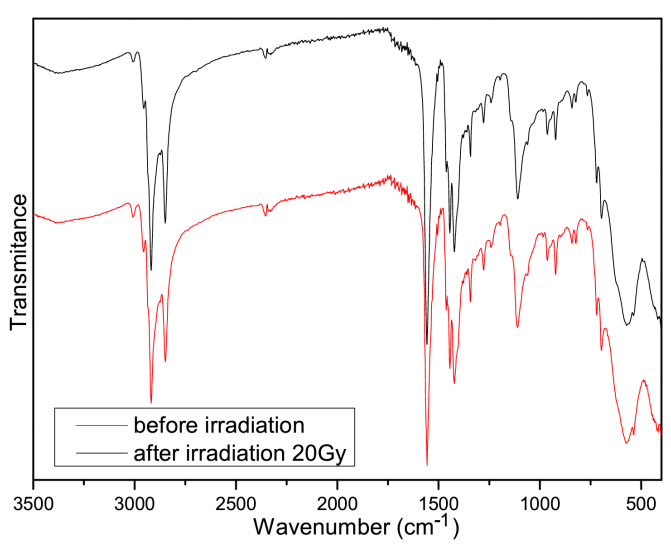

Fig. 3. FTIR spectra of magnetite coated with natrium oleate and PEG (molar weight 1000 and $0.25 \mathrm{~g}$ PEG per $1 \mathrm{~g}$ of $\mathrm{Fe}_{3} \mathrm{O}_{4}$ ) before irradiation and after irradiation with $20 \mathrm{~Gy}$. The spectra are shifted vertically for clarity. 
of the surfactants as well as the magnetite particles are stable under irradiation and no destroying processes occur due to the irradiation.

\section{Conclusion}

In summary, the magnetization measurements showed that electron irradiation with 20 Gy caused about $10 \%$ reduction of the saturation magnetization. The obtained results showed that the radiation causes aggregation of the particles and consequently their sedimentation. We can conclude that the molar weight as well as added amount of PEG does not influence the magnetic properties of the magnetic fluids. Moreover, after first sedimentation process that occurs after irradiation, there is no further sedimentation and all samples are time stable at least 1 month after irradiation.

\section{Acknowledgments}

This work was supported by the Slovak Academy of Sciences grants VEGA 2/0077/09 and Nanofluid, Centre of Excellence, Ministry of Education of Slovakia - Agency for Structural Fonds of EU in frame of project Development of technology of magnetic fluids for biomedical applications No. 26220220005 and 6220120021, and by Ministry of Education and Science of Ukraine in the framework of project DB-715.

\section{References}

[1] S.S. Papell, U.S. Patent 3, 215, 572 (1965).

[2] R.E. Rosensweig, J.W. Nestor, R.S. Timmins, Mater. Assoc. Direct Energy Convers. Proc. Symp. AIChE-I. Chem. Ser. 5, 104 (1965).

[3] S.I. Park, J.H. Lim, H.I. Yun, J.S. Roh, C.G. Kim, C.O. Kim, Phys. Status Solidi B 241, 16624 (2004).

[4] M. Chanana, Z.W. Mao, D.Y. Wang, J. Biomed. Nanotechnol. 5, 6526 (2009).

[5] P. Kopcansky, J. Cernak, T. Tima, A. Zentko, M. Timko, P. Slanco, J. Magn. Magn. Mater. 85, 103 (1990)

[6] I. Apostolova, J.M. Wesselinova, Phys. Status Solidi B 246, 1925 (2009).

[7] A. Jordan, R. Scholz, K. Maier-Hauff, M. Johannsen, P. Wust, J. Nadobny, H. Schirra, H. Schmidt, S. Deger, S. Loening, W. Lanksch, R. Felix, J. Magn. Magn. Mater. 225, 118 (2001).

[8] M. Johannsen, U. Gneveckow, L. Eckelt, A. Feussner, N. Waldofner, R. Scholz, S. Deger, P. Wust, S.A. Loening, A. Jordan, Int. J. Hyperthermia 21, 637 (2005).

[9] M. Johannsen, B. Thiesen, U. Gneveckow, K. Taymoorian, N. Waldofner, R. Scholz, S. Deger, K. Jung, S.A. Loening, A. Jordan, Prostate 66, 97 (2006).

[10] N. Tomašovičová, I. Haysak, M. Koneracká, J. Kováč, M. Timko, V. Závišová, A. Okunev, A. Parlag, A. Fradkin, P. Kopčanský, arXiv:1004.3448v2 [cond-mat.soft]. 